\title{
EVALUASI FAKTOR KEGAGALAN SISTEM INFORMASI PADA KESIAPAN PENERAPAN E-GOVERNMENT: STUDI LITERATUR
}

\author{
Agung R Pamungkas ${ }^{1}$, Lukito E Nugroho ${ }^{2}$, Selo Sulistyo ${ }^{3}$ \\ ${ }^{1,2,3}$ Departemen Teknik Elektro dan Teknologi Informasi, Universitas Gadjah Mada Yogyakarta \\ Email: ${ }^{1}$ agung.pamungkas@mail.ugm.ac.id, ${ }^{2}$ lukito@ugm.ac.id, ${ }^{3}$ selo@ugm.ac.id
}

(Naskah masuk: 3 September 2020, diterima untuk diterbitkan: 16 September 2020)

\begin{abstract}
Abstrak
Penerapan sistem informasi pada jajaran pemerintah dan lembaga dibawahnya diharapkan dapat menjadi kunci suskses Sistem Pemerintah Berbasis Elektronik (SPBE). Namun demikian, banyak institusi pemerintah yang menemui kegagalan dalam menerapkan sistem informasi. Oleh karena hal tersebut, maka perlu dilakukan kajian untuk menganalisis kegagalan sistem informasi pada studi-studi yang sudah ada. Penelitian ini adalah studi literatur dari 36 jurnal dan artikel internasional mengenai faktor penyebab kegagalan sistem informasi di jajaran pemerintah dengan tujuan menghasilkan dimensi kegagalan, indikator, serta model evaluasi sistem informasi. Dari analisis yang dilakukan, dihasilkan 5 dimensi kegagalan sistem informasi yaitu Organisasi, SDM, Teknologi, Layanan dan Proses dimana masing-masing dimensi tersebut memiliki indikator yang digunakan untuk mengukur tingkat kegagalan sistem informasi. Penelitian ini juga merumuskan 8 model evaluasi sistem informasi sesuai dengan literatur yang dikaji yaitu TAM, TRA dan UTAUT yang termasuk dalam fokus penggunaan; HOT-Fit dan ITPOSMO yang termasuk dalam fokus kemanfaatan serta EUCS dan EIM yang termasuk dalam fokus kepuasan pengguna.
\end{abstract}

Kata kunci: e-government, evaluasi, kegagalan, sistem informasi, model evaluasi

\section{EVALUATION OF INFORMATION SYSTEM FAILURE FACTORS ON READINESS OF E-GOVERNMENT IMPLEMENTATION: A LITERATURE REVIEW}

\begin{abstract}
Information system (IS) implementation in the public sector is expected to be the key of success for e-government. However, many government facing a failure in implementing IS. Therefore, it is necessary to conduct a study to analyze the failure of information systems in existing studies. This research is a systematic literature review of 36 international journals and articles on the factors causing the IS failure in government with the aim of formulating failure dimensions, indicators, and information systems evaluation models. As a result, 5 dimensions IS failure are generated, namely Organization, Human Resources, Technology, Services and Processes, each of which has indicators used to measure the failure rate of information systems. This study also formulates 8 IS evaluation models according to the literature studied, namely TAM, TRA and UTAUT which are included in the focus of use; HOT-Fit and ITPOSMO which are included in the focus of usability and EUCS and EIM which are included in the focus of user satisfaction.
\end{abstract}

Keywords: e-government,evaluation, failure, information system, evaluation method

\section{PENDAHULUAN}

E-Government adalah penggunaan dan pemanfaatan teknologi informasi dalam administrasi publik untuk mempersingkat dan mengintegrasikan alur dan proses kerja, mengelola data dan informasi secara efektif, meningkatkan layanan publik, serta memperluas saluran komunikasi untuk pemberdayaan dan partisipasi masyarakat [1]. Pada sektor pemerintah, pengembangan dan pemanfaatan sistem informasi sebagai wujud implementasi $e$ government yang kemudian disebut dengan Sistem
Pemerintahan Berbasis Elektronis (SPBE) tak selalu lancar dan sesuai harapan. Banyak sistem informasi yang gagal diimplementasikan dikarenakan berbagai hal. Menurut Meiyanti et al [2], tantangan pada implementasi e-government bisa menyebabkan kegagalan. Selanjutnya, kegagalan tersebut diukur melalui presentase yaitu 35\% gagal total, $50 \%$ gagal sebagian dan hanya $15 \%$ yang menuai keberhasilan [2]. Disisi lain, pemerintah terus melakukan investasi yang besar dalam pengadaan sistem informasi dengan tujuan untuk mendukung dan meningkatkan fungsi 
internal serta komunikasi dan transaksi dengan pihak eksternal [3].

Dengan tingginya kegagalan dalam penerapan sistem informasi khususnya pada sektor pemerintah, maka perlu dilakukan analisis faktor-faktor penyebab kegagalan beserta model evaluasinya. Dengan melakukan analisis faktor - faktor kegagalan dalam menerapkan sistem informasi, maka kesiapan penerapan sistem informasi pada pemerintah dapat dimaksimalkan. Sehingga konsep e-government dapat dilaksanakan dengan baik dan berhasil. Dengan mengetahui gap dari kegagalan atau kesuksesan penerapan sistem informasi, kesiapan penerapan sistem informasi berikutnya akan lebih terukur dan matang untuk menghindari kegagalan dimasa yang akan datang [4].

Studi literatur mengenai keberhasilan $e$ government sudah dilakukan oleh peneliti sebelumnya seperti Muflihah dan Susanto [5] yang meneliti mengenai faktor yang mempengaruhi warga dan pemerintah dalam adopsi e-government. Studi juga dilakukan oleh Masyhur [6] yang melakukan analisis terhadap kajian e-government di Indonesia menggunakan perspektif dimensi pemeringkatan $e$ government Indonesia (PeGI). Namun demikian, studi-studi tersebut diatas masih membahas $e$ government secara umum dan belum melakukan analisis terhadap kegagalan sistem informasi secara spesifik sebagai bagian dari penerapan e-government. Oleh karena hal tersebut diatas, maka perlu dilakukan analisis terhadap faktor-faktor yang menyebabkan kegagalan sistem informasi pada sektor pemerintah guna meningkatkan kesiapan penerapan $e$ government.

Penelitian ini merupakan studi literatur yang membahas faktor-faktor yang sangat mempengaruhi kegagalan pada suatu organisasi pemerintah dalam mengembangkan dan menerapkan sistem informasi. Penelitian ini mengelompokan faktor-faktor kegagalan berdasarkan literatur kedalam beberapa dimensi beserta indikatornya. Selain mendefinisikan dimensi dan indikator kegagalan, dijabarkan pula model - model evaluasi sistem informasi untuk mengukur kesuksesan maupun kegagalan sistem tersebut berdasarkan fokus evaluasinya. Penelitian ini diharapkan dapat menjadi salah satu bahan pedoman pemerintah dalam melakukan evaluasi sistem informasi yang sudah ada, maupun untuk mempersiapkan pengadaan dan pengembangan sistem informasi secara matang dan terukur guna meghindari kegagalan.

\section{METODE PENELITIAN}

Metodologi yang digunakan pada penelitian ini adalah systematic literature review dengan menggunakan rujukan Kitchenham [7]. systematic literature review merupakan proses identifikasi, evaluasi, dan penafsiran dari penelitian-penelitian yang relevan dengan pertanyaan penelitian, atau topik, atau fenomena tertentu [7]. Adapun langkah dan tahapan penelitian adalah sebagai berikut :

\subsection{Tujuan Penelitian}

Tujuan utama dari penelitian ini adalah melakukan studi literatur untuk mengetahui faktorfaktor apa saja yang sangat berpengaruh pada kegagalan penerapan sistem informasi di sektor pemerintah (e-Government) yang dirumuskan dalam beberapa dimensi dan indikator. Selain itu, penelitian ini juga bertujuan untuk menjabarkan model-model evaluasi sistem informasi dan pengelompokanya berdasarkan fokus evaluasinya. Tujuan penelitian tersebut untuk menjawab masalah penelitian yaitu tingginya tingkat kegagalan pemerintah dalam menerapkan sistem informasi.

\subsection{Pertanyaan Penelitian}

Untuk mewujudkan tujuan penelitian tersebut diatas, maka dirumuskan beberapa pertanyaan penelitian yang kemudian disebut Research Questions (RQ) sebagai berikut :

RQ1 : "Apa saja dimensi kegagalan sistem informasi pada pemerintah dalam rangka menerapkan e-government?". Dimensi kegagalan digunakan sebagai kerangka dalam melakukan pengukuran atau evaluasi sistem informasi dengan perspektif yang luas dan abstrak dimana memiliki cakupan beberapa faktor kegagalan yang saling berkaitan satu sama lain dan dikelompokkan berdasarkan substansi masingmasing faktor.

RQ2 : “Apa saja indikator pada masing-masing dimensi kegagalan sistem informasi pada pemerintah dalam rangka menerapkan e-government?". Indikator kegagalan merupakan suatu alat yang lebih konkrit dari dimensi kegagalan dalam melakukan pengukuran atau evaluasi pada sistem informasi. Indikator tersebut digunakan sebagai acuan dalam menyusun kuisioner, wawancara maupun observasi dalam rangka pengumpulan data guna melakukan pengukuran atau evaluasi terhadap faktor-faktor kegagalan. Dengan indikator, maka faktor-faktor kegagalan dapat diukur secara komperhensif.

RQ3 : "Apa saja model evaluasi sistem informasi ?". Model evaluasi diperlukan untuk melakukan pengukuran secara empiris terhadap sistem informasi dimana model-model tersebut sudah diteliti dan dikaji oleh para peneliti sebelumnya dan digunakan sebagai body of knowledge maupun framework dalam pengukuran atau evaluasi sistem informasi.

RQ4. : “Apa saja fokus pada model evaluasi sistem informasi?”. Perumusan fokus model evaluasi 
berdasarkan literatur dilakukan untuk mencari kesesuaian antara model evaluasi yang digunakan dengan dimensi, indikator maupun tujuan dari evaluasi itu sendiri agar dapat dihasilkan bahan pengambilan keputusan yang tepat.

\subsection{Pencarian literatur}

Proses pencarian literatur yang relevan dengan tujuan dan pertanyaan penelitian dilakukan pada 3 database jurnal dan artikel penelitian yaitu Scopus, Sciencedirect dan Researchgate. Adapun kata kunci yang digunakan untuk melakukan pencarian terhadap judul maupun abstrak penelitian adalah "government information system failure", "Information System evaluation model" serta "IS evaluation method". Tahun terbit penelitian yang dicari kemudian dibatasi antara tahun 2010 sampai dengan tahun 2020. Adapun jurnal dan artikel yang diunduh berdasarkan hasil pencarian tersebut diatas berjumlah 113 berkas dengan rincian yang tertera pada Tabel 1 .

\begin{tabular}{cc} 
Tabel 1. Hasil pencarian jurnal dan artikel \\
\hline Database & Jumlah berkas \\
\hline Scopus & 51 \\
Sciencedirect & 24 \\
Researchgate & 38 \\
Total & 113 \\
\hline
\end{tabular}

\subsection{Pemilihan literatur}

Setelah dilakuan proses pencarian dan pengumpulan (unduh) jurnal dan artikel, maka langkah selanjutnya adalah melakukan pemilihan literatur yang sesuai dengan kriteria inklusi maupun eksklusi.

Kriteria inklusi :

- Objek penelitian merupakan negara, pemerintah (pusat maupun daerah), serta organisasi, institusi dan lembaga dibawah pemerintah.

- Penelitian menjabarkan faktor kegagalan maupun keberhasilan sistem informasi dan atau model evaluasi sistem informasi.

- Penelitian menggunakan bahasa internasional dan bersifat peer-review.

Kriteria eksklusi :

- Penelitian berupa tugas akhir, skripsi maupun tesis yang tidak dipublikasikan.

- Penelitian yang tidak menjelaskan faktor kegagalan secara dimensional dan terstruktur.

\begin{tabular}{ll}
\multicolumn{2}{c}{ Tabel 2. Hasil pemilahan jurnal dan artikel } \\
\hline Database & Jumlah berkas \\
\hline Scopus & 18 \\
Sciencedirect & 11 \\
Researchgate & 07 \\
Total & 36 \\
\hline
\end{tabular}

Setelah dilakukan pemilihan berdasarkan kriteria diatas, maka didapatkan literatur sebanyak 36 berkas untuk dilakukan studi seperti yang ditampilkan pada Tabel 2.

\subsection{Analisis}

Analisis dilakukan dengan cara membuat rangkuman dan rumusan temuan pada literatur berupa faktor-faktor penyebab kegagalan sistem informasi. Kemudian rangkuman tersebut dikelompokkan menjadi beberapa dimensi beserta indikatornya. Selain itu, model evaluasi sistem informasi juga dilakukan rumusan dan dilakukan pengelompokan berdasarkan fokus evaluasinya.

\section{HASIL DAN PEMBAHASAN}

Berdasarkan tahapan-tahapan sesuai dengan metodologi penelitian, literatur dikelompokkan menjadi 2 pokok bahasan yaitu analisis mengenai dimensi dan indikator kegagalan untuk menjawab pertanyaan penelitian RQ1 dan RQ2 serta pokok bahasan yang kedua yaitu analisis model evaluasi sistem informasi beserta fokus evaluasinya untuk menjawab pertanyaan penelitian RQ3 dan RQ4.

\begin{tabular}{|c|c|}
\hline Dimensi & Faktor Kegagalan \\
\hline Organisasi & $\begin{array}{l}\text { Keuangan [8], [14]; } \\
\text { Hukum [8], [11]; } \\
\text { Politik [8], [10], [13]; } \\
\text { Regulasi [9], [11], [14]; } \\
\text { Dukungan \& Komitmen Pimpinan [10], [11], } \\
\text { [24], [25], [13]-[15], [17], [18], [20], [21], } \\
\text { [23],[12]; } \\
\text { Strategi [10]-[14], [16]; } \\
\text { Manajemen Resiko [12], [23], [24] }\end{array}$ \\
\hline Sumber Daya & Sosial \& Budaya [8], [13]; \\
\hline Manusia & motivasi [9], [12], [20]; \\
\hline$(\mathrm{SDM})$ & $\begin{array}{l}\text { Kompetensi TIK [10], [12], [13], [15], [16], [20], } \\
\text { [23]; } \\
\text { Pendidikan \& Pelatihan [10], [16], [20], [23] }\end{array}$ \\
\hline Teknologi & $\begin{array}{l}\text { Infrastruktur [8], [12]-[14], [20], [21]; } \\
\text { Keamanan [11], [13], [14], [17], [18] }\end{array}$ \\
\hline Layanan & $\begin{array}{l}\text { Komunikasi [10], [12], [15], [16], [18], [20], } \\
{[22]-[24] \text {; }} \\
\text { Kualitas layanan [9], [16], [19], [21]; } \\
\text { Dukungan layanan [20], [21]; } \\
\text { Kesiapan Informasi [13], [19] }\end{array}$ \\
\hline Proses & $\begin{array}{l}\text { Kompleksitas [9], [17], [22], [25]; } \\
\text { Perencanaan [10]-[14], [16], [20], [23]; } \\
\text { Business Process Re-engineering (BPR) [10], } \\
{[13],[16],[25] \text {; }} \\
\text { Kebutuhan Pengguna [11], [13], [17], [22]; } \\
\text { Interoperabilitas \& Integrasi [13], [14], [16], } \\
{[17],[20],[21]} \\
\text { Manajemen Proyek [12], [15], [16], [18], [22]- } \\
{[25]}\end{array}$ \\
\hline
\end{tabular}

Pada pokok bahasan yang pertama, ekstraksi dan analisis dilakukan pada 18 dari 36 literatur kemudian dilakukan rangkuman terhadap temuan-temuan mengenai faktor-faktor kegagalan sistem informasi yang diadakan maupun dikembangkan oleh pemerintah dan organisasi publik dibawah pemerintah seperti fasilitas kesehatan milik pemerintah, pendidikan (universitas) negeri, dan organisasi publik lainya yang menggunakan kaidahkaidah e-government. 
Dari rangkuman faktor kegagalan, sebanyak 12 literatur merupakan studi mengenai faktor kegagalan pada pemerintah [8], [9], [18], [19], [10]-[17] dan 6 literatur merupakan studi faktor kegagalan pada lembaga dibawah pemerintah [20]-[25]. Secara umum, faktor-faktor kegagalan pada dua studi ini sama dan mirip. Namun pada sektor pemerintah (pusat) terdapat faktor politik [8], [10], [13] yang tidak dirumuskan pada lembaga dibawah pemerintah. Hal tersebut menandakan bahwa pemerintah memiliki cakupan yang lebih luas dan memiliki pertimbangan yang lebih banyak disisi kebijakan dibandingkan organisasi dibawahnya.

Tabel 3 menjawab pertanyaan penelitian RQ1 yaitu "Apa saja dimensi kegagalan sistem informasi pada pemerintah dalam rangka menerapkan $e$ government?". Tabel tersebut menunjukkan pengelompokan faktor-faktor kegagalan sistem informasi yang diperoleh dari studi literatur kedalam 5 dimensi yaitu Organisasi, SDM, Teknologi, Layanan dan Proses.

Untuk menjawab pertanyaan penelitian RQ2 : "Apa saja indikator pada masing-masing dimensi kegagalan sistem informasi pada pemerintah dalam rangka menerapkan e-government?" maka dilakukan telaah terhadap faktor-faktor kegagalan yang diperoleh dari studi literatur. Beberapa faktor yang relevan dilakukan penggabungan menjadi satu indikator. Sedangkan faktor yang terlalu luas cakupannya dilakukan penjabaran menjadi indikator yang lebih fokus. Hal ini dimaksudkan agar dimensi yang dirumuskan dapat dilakukan evaluasi menggunakan model-model evaluasi secara fleksibel.

\begin{tabular}{ll}
\multicolumn{2}{c}{ Tabel 4. Indikator kegagalan sistem informasi } \\
\hline \multicolumn{1}{c}{ Indikator } & \multicolumn{1}{c}{ Dimensi } \\
\hline Dukungan \& Komitmen & Organisasi \\
Pimpinan & \\
Hukum, Politik \& Regulasi & \\
Keuangan & \\
Strategi \& Manajemen Resiko & \\
Sosial \& Budaya & Sumber Daya \\
motivasi & Manusia (SDM) \\
Kompetensi TIK & \\
Pendidikan \& Pelatihan & \\
Pusat Data & Teknologi \\
Konektifitas & \\
Sarana \& Prasarana Pengguna & \\
Keamanan \& Privasi & \\
Komunikasi & Layanan \\
Kualitas \& Dukungan layanan & \\
Data \& Informasi & \\
Perencanaan & Proses \\
Kompleksitas & \\
Kebutuhan Pengguna \& & \\
Business Process Re- & \\
engineering (BPR) & \\
Interoperabilitas \& Integrasi & \\
Manajemen Proyek & \\
\end{tabular}

Dengan adanya penggabungan serta penjabaran faktor-faktor kegagalan sistem informasi yang berasal dari studi literatur menjadi indikator dimensi kegagalan sistem informasi, maka dihasilkan 20 indikator yang terdiri dari 4 indikator pada dimensi organisasi, 4 indikator pada dimensi SDM, 4 indikator pada dimensi teknologi, 3 indikator pada dimensi layanan serta 5 indikator pada dimensi proses. Adapun detail dari masing-masing indikator, dapat dilihat pada Tabel 4.

Pada penelitian ini, dilakukan pula studi literatur untuk mengetahui model atau framework apa saja yang banyak digunakan untuk melakukan evaluasi sistem informasi. Ekstraksi dilakukan pada 20 dari 36 literatur yang diperoleh. Untuk menjawab pertanyaan penelitian RQ3 : "Apa saja model evaluasi sistem informasi ?", dilakukan rangkuman dan didapatkan hasil berupa 8 model evaluasi sistem informasi yaitu TAM, TRA, ISSM, UTAUT, EUCS, HOT-Fit, ITPOSMO dan EIM. Detail model evaluasi berdasarkan literatur dapat dilihat pada Tabel 5 .

Tabel 5. Model evaluasi berdasarkan literatur

\begin{tabular}{|c|c|}
\hline Model Evaluasi & Referensi \\
\hline Technology & Elkhensin [26], Al-Emran [27], \\
\hline $\begin{array}{l}\text { Acceptance Model } \\
\text { (TAM) }\end{array}$ & Chen [28], Çelik [29] \\
\hline $\begin{array}{l}\text { Theory of Reasoned } \\
\text { Action (TRA) }\end{array}$ & $\begin{array}{l}\text { Mohanachandran [30], Otieno } \\
\text { [31], }\end{array}$ \\
\hline $\begin{array}{l}\text { IS success model } \\
\text { (ISSM) }\end{array}$ & $\begin{array}{l}\text { Angelina [32], Steinbacher [33], } \\
\text { Floropuolos [19] }\end{array}$ \\
\hline $\begin{array}{l}\text { Unified Theory of } \\
\text { Acceptance and Use }\end{array}$ & $\begin{array}{l}\text { Gunawan [34], Shiferaw [35], } \\
\text { Venkatesh [36] }\end{array}$ \\
\hline $\begin{array}{l}\text { of Technology } \\
\text { (UTAUT) }\end{array}$ & \\
\hline $\begin{array}{l}\text { End-User Computing } \\
\text { Satisfaction (EUCS) }\end{array}$ & Pauluzzo [37], Prasetyo [38] \\
\hline Human Organization & Erlirianto [39] \\
\hline $\begin{array}{l}\text { Technology }- \text { Fit } \\
\text { (HOT-Fit) }\end{array}$ & \\
\hline ITPOSMO & $\begin{array}{l}\text { Napitupulu [40], Fauzie [41], } \\
\text { Elkadi [17] }\end{array}$ \\
\hline $\begin{array}{l}\text { Equity } \\
\text { Implementation } \\
\text { Model (EIM) }\end{array}$ & Kim [42], Hess [43] \\
\hline
\end{tabular}

Banyaknya model evaluasi sistem informasi yang dirumuskan oleh para peneliti dimaksudkan untuk mengukur sejauh mana sistem tersebut memenuhi harapan dan tujuan. Hal tersebut disebabkan oleh keragaman konteks dan perspektif dalam melakukan evaluasi sistem informasi [44]. Suatu organisasi dapat melakukan evaluasi sistem informasi menggunakan model yang sesuai dengan konteks dan perspektif masing-masing. Pada penelitian ini, dilakukan klasifikasi evaluasi sistem informasi kedalam 3 fokus evaluasi yaitu fokus penggunaan, fokus kepuasan pengguna, serta fokus pada kemanfaatan.

Dari 8 model yang telah dilakukan studi, TAM, TRA dan UTAUT diklasifikasikan kedalam fokus penggunaan. HOT-Fit dan ITPOSMO diklasifikasikan dalam fokus kemanfaatan. Serta EUCS dan EIM yang diklasifikasikan dalam fokus kepuasan pengguna. Hasil dari klasifikasi tersebut menjawab pertanyaan penelitian RQ4 yaitu "Apa saja fokus pada model evaluasi sistem informasi?". 


\subsection{Dimensi dan Indikator kegagalan sistem informasi}

Untuk dapat memetakan penyebab kegagalan sistem informasi, maka dibuatlah dimensi-dimensi sebagai instrumen pengukuran pada sistem informasi tersebut. Pada tiap dimensi, kemudian dijabarkan kedalam indikator yang merupakan substansi yang lebih spesifik dimana memuat kriteria-kriteria pengukuran yang lebih nyata. Penelitian ini merumuskan 5 dimensi kegagalan sistem informasi antara lain sebagai berikut :

\subsubsection{Dimensi Organisasi}

Kesuksesan suatu penerapan sistem informasi sangat dipengaruhi oleh faktor-faktor organisasional dalam sebuah pemerintahan baik pemerintah pusat, pemerintah daerah, maupun organisasi-organisasi dibawah pemerintah. Hal ini tak dapat dipungkiri karena semua kegiatan yang ada dalam pemerintah sangat terstruktur dan cenderung kaku sehingga kesuksesan sistem informasi sangat tergantung pada visi, misi, serta arah kebijakan pimpinan tertinggi yang dipengaruhi oleh para pemangku kepentingan. Dalam dimensi ini, terdapat 4 indikator yang dapat digunakan sebagai instrumen pengukuran antara lain:

- Dukungan \& Komitmen pimpinan. Merupakan suatu itikad dan konsistensi pimpinan untuk menerapkan sistem informasi dalam organisasinya secara nyata.

- Hukum, Politik \& Regulasi. Adalah upaya pemerintah untuk melandasi suatu penerapan sistem informasi agar dapat teratur, tertata, serta jelas ruang lingkupnya dalam kerangka hukum yang sah guna mencapai tujuan organisasi.

- Keuangan. Adalah pembiayaan yang bersifat modal, operasional maupun insidental guna mewujudkan penerapan sistem informasi.

- Strategi \& Manajemen Resiko. Merupakan suatu strategi organisasi yang berbentuk rencana jangka panjang organisasi, rencana strategis, master plan serta prosedur standar operasional (PSO) yang mengatur tahapan serta prosedur dalam menerapkan sistem informasi untuk mencapai tujuan dan meminimalisir resiko.

\subsubsection{Dimensi Sumber Daya Manusia (SDM)}

Dimensi ini merupakan dimensi yang mencakup faktor-faktor manusia sebagai pelaksana teknis maupun pengguna. Menurut hasil studi literatur, Sumber Daya Manusia (SDM) menjadi salah satu dimensi yang kritikal selain organisasi. Suatu sistem informasi perlu memiliki SDM yang profesional baik sebagai pengelola maupun sebagai pengguna karena peran manusia itu sendiri sebagai brainware dari sistem informasi. Kapasitas SDM suatu organisasi harus selalu ditingkatkan untuk mengimbangi perubahan teknologi yang sangat cepat dan masif. Beberapa indikator untuk mengukur SDM antara lain adalah :

- Sosial \& Budaya. Adalah pengalaman, kebiasaan, paradigma serta pola pikir manusia (pegawai \& masyarakat) dalam memecahkan suatu masalah maupun menjalankan suatu proses bisnis organisasi menggunakan sistem informasi.

- Motivasi. Adalah hasrat dan keinginan manusia (pegawai \& masyarakat) untuk menggunakan sistem informasi tanpa tekanan maupun paksaan.

- Kompetensi TIK. Merupakan kemampuan umum yang dimiliki manusia (pegawai \& masyarakat) untuk menggunakan teknologi informasi dan komunikasi.

- Pendidikan \& Pelatihan. Adalah pembekalan kemampuan khusus untuk mengoperasikan sistem informasi tertentu maupun ilmu pengetahuan spesifik yang berkaitan dan relevan terhadap sistem informasi yang diterapkan pada suatu organisasi.

\subsubsection{Dimensi Teknologi}

Teknologi merupakan dimensi dalam kegagalan sistem informasi yang mencakup seluruh aspek yang berhubungan dengan teknis dan infrastruktur teknologi informasi dan komunikasi (TIK). Dimensi ini biasanya berkaitan erat dengan keuangan, dimana membutuhkan alokasi anggaran yang terbesar dibandingkan dengan aspek-aspek lain. Dalam penerapanya, pemerintah dapat mengelola TIK sendiri maupun dikelola oleh pihak ketiga (manage services, cloud, dll). Adapun untuk dapat mengukur kegagalan maupun kesuksesan sistem informasi pada dimensi teknologi, indikator yang daigunakan adalah sebagai berikut :

- Pusat Data. Merupakan pusat pengelolaan dimana data diproses dan disimpan serta pusat pengelolaan jaringan atau konektifitas pada suatu organisasi.

- Konektifitas. Adalah jaringan yang menghubungkan antara pengguna sistem informasi dengan pusat data dalam melakukan pertukaran data. Bisa berupa jaringan lokal, intranet, internet, maupun jenis jaringan lainya yang ditetapkan oleh organisasi.

- Sarana \& Prasarana Pengguna. Adalah semua perangkat wajib dan pendukung yang 
dibutuhkan untuk mengoperasikan sistem informasi.

- Keamanan \& Privasi. Merupakan jaminan keamanan data dalam operasional sistem informasi untuk memastikan integritas data dan privasi.

\subsubsection{Dimensi Layanan}

Sistem informasi dalam suatu organisasi yang sudah diadakan maupun dikembangkan perlu dibarengi pula dengan layanan yang mendukung sistem informasi itu sendiri. Organisasi perlu menjamin layanan sistem informasi agar dapat tetap berjalan sesuai harapan dan mengatasi masalahmasalah baik teknis maupun non teknis dalam operasional sistem informasi. Adapun indikator pada dimensi layanan adalah sebagai berikut :

- Komunikasi. Yaitu upaya organisasi untuk melakukan komunikasi terhadap pihak-pihak yang berkepentingan dan berkaitan dengan proses bisnis pada sistem informasi baik sebelum maupun setelah sistem tersebut diadakan. Komunikasi tersebut dapat berupa sosialisasi, Focus Group Discussion (FGD), edaran, maupun bentuk komunikasi lain yang ditetapkan organisasi.

- Kualitas \& Dukungan layanan. Merupakan dukungan layanan yang diberikan kepada pengguna untuk menjamin layanan yang diberikan. Jaminan kualitas layanan dapat dinyatakan dalam service level agreement (SLA), sementara dukungan layanan dapat direalisasikan dengan helpdesk dan technical support untuk menangani masalah yang terjadi dalam operasional sistem informasi.

- Data \& Informasi. Merupakan kesesuaian keluaran (output) sistem informasi dengan kebutuhan pengguna, organisasi, maupun pemangku kepentingan.

\subsubsection{Dimensi Proses}

Dimensi ini merupakan aspek-aspek yang berkaitan dengan proses pengadaan maupun pengembangan sistem informasi mulai dari perencanaan sampai dengan proses pengembangan maupun pengadaanya (procurement). Adapun indikator pada dimensi proses antara lain adalah :

- Perencanaan. Adalah proses perencanaan kegiatan pengadaan atau pengembangan sistem informasi. Proses ini dinyatakan pada rencana dan program kerja organisasi.
- Kompleksitas. Merupakan tingkat kerumitan/kemudahan dalam penggunaan sistem informasi baik berdasarkan antar muka maupun proses kerjanya.

- Kebutuhan Pengguna \& Business Process Reengineering (BPR). Adalah proses pengembangan atau pengadaan sistem informasi yang berbasis kebutuhan serta reengineering dari proses lama menjadi proses baru yang lebih menguntungkan bagi organisasi.

- Interoperabilitas \& Integrasi. Adalah kemampuan sistem informasi untuk bertukar data dan atau terintegrasi dengan sistem lain.

- Manajemen Proyek. Adalah kemampuan organisasi dalam melakukan manajemen dalam proses pengadaan sistem informasi.

\subsection{Model evaluasi sistem informasi}

\subsubsection{Fokus Penggunaan}

Pada fokus evaluasi penggunaan, kegagalan atau kesuksesan suatu sistem informasi diukur dari beberapa variabel yang berpengaruh pada penggunaan sistem. Dengan variabel-variabel tersebut, maka model evaluasi sistem informasi dengan fokus penggunaan cocok digunakan untuk melakukan evaluasi dimana faktor-faktor selain SDM tidak mempengaruhi kesuksesan/kegagalan serta digunakan untuk mengetahui pengaruh dari masingmasing variabel pada model evaluasi terhadap keberhasilan suatu sistem informasi dari perspektif pengguna. Model evaluasi dengan fokus penggunaan cocok digunakan untuk melakukan evaluasi sistem informasi untuk mengetahui tingkat penerimaan pengguna terhadap sistem informasi yang baru. Dalam implementasi e-government, evaluasi ini dapat digunakan untuk mengukur penerimaan masyarakat terhadap layanan publik berbasis digital baik layanan informasi publik, website Pemerintah, layanan administrasi, perizinan dan layanan-layanan lainya. Yang termasuk model evaluasi pada fokus penggunaan antara lain TRA, TAM dan UTAUT.

Theory of Reasoned Action (TRA) merupakan cikal bakal dari TAM. TRA digunakan untuk melakukan evaluasi sistem informasi menggunakan pendekatan perilaku manusia dimana diyakini bahwa keyakinan dapat mempengaruhi sikap dan norma sosial dan merubah bentuk keinginan berperilaku pada masing-masing individu. TRA memiliki 2 konstruk utama yaitu :

- The attitude toward behavior. Merupakan korelasi antara keyakinan dengan perilaku.

- Subjective norm. adalah tekanan sosial yang mendesak seseorang untuk menunjukan suatu perilaku. 
Technology Acceptance Model (TAM) adalah suatu model yang dikembangkan dari TRA dan banyak digunakan oleh peneliti maupun praktisi untuk melakukan evaluasi sitem informasi dengan perspektif penerimaan pengguna. Model yang dikembangkan oleh Davis [45] ini sering digunakan untuk menjabarkan faktor-faktor mendasar yang memotivasi pengguna untuk menerima dan mengadopsi sistem informasi baru. TAM memiliki 3 variabel untuk melakukan analisa maupun evaluasi sistem informasi yaitu :

- Perceived Usefulness. Yaitu level dimana manusia memiliki kepercayaan terhadap sistem informasi dimana sistem tersebut mampu meningkatkan kinerja.

- Perceived Ease of Use. Merupakan level dimana manusia memiliki kepercayaan bahwa dengan menggunakan sistem informasi akan memudahkanya.

- Intention To Use. Adalah kecenderungan manusia untuk menggunakan sistem informasi.

UTAUT dirumuskan oleh Venkatesh [46] dengan mengembangkan beberapa model evaluasi yang sudah ada. Model ini memiliki 4 konstruk yaitu:

- Performance Expectancy. Merupakan aspek yang digunakan untuk mengukur tingkat kepercayaan manusia bahwa sistem informasi dapat membantu kinerja pekerjaanya.

- Effort Expectancy. Yaitu ukuran usaha tiap individu dalam menggunakan sistem informasi.

- Social Influence. Adalah level seseorang yang menganggap penting orang lain yang meyakinkan atau mempengaruhi diri untuk menggunakan sistem informasi.

- Facilitating Condition. Adalah level keyakinan seseorang bahwa sarana dan prasarana disediakan untuk mendukung pekerjaanya dalam sistem informasi.

\subsubsection{Fokus Kepuasan Pengguna}

Model evaluasi yang berfokus pada kepuasan pengguna memiliki keyakinan bahwa berhasil atau tidaknya suatu sistem informasi dinilai dari puas atau tidaknya pengguna terhadap sistem tersebut. Berbeda dari model evaluasi yang berfokus pada penerimaan pengguna, model evaluasi yang termasuk dalam fokus ini lebih menitikberatkan pada kepuasan pengguna terhadap sistem informasi yang telah digunakan selama periode tertentu. Pengukuran kepuasan pengguna dimaksudkan untuk melakukan evaluasi terhadap sistem informasi yang sudah ada dalam rangka peningkatan, perbaikan, maupun penghentian sistem informasi. Model-model evaluasi ini dapat digunakan dalam implementasi $e$ government dalam melakukan pengukuran capaian kinerja yang berhubungan dengan layanan publik berbasis digital. Model evaluasi yang termasuk kedalam fokus kepuasan pengguna adalah EUCS dan EIM.

End-User Computing Satisfaction (EUCS) adalah evaluasi dampak dan kognitif yang dilakukan terhadap end user untuk mengukur kepuasan dalam menggunakan sistem informasi. EUCS dirumuskan oleh Doll dan Torkzadeh [47] pada tahun 1988. Model ini memiliki 5 konstruk yaitu :

- Content. Merupakan konstruk yang merepresentasikan informasi yang disediakan kepada end user.

- Accuracy. Adalah konstruk yang mengukur ketepatan dari informasi.

- Format. Adalah tata letak atau antar muka dari sistem informasi yang digunakan untuk mempresentasikan konten.

- Ease of use. Adalah kemudahan pengguna dalam menggunakan sistem informasi.

- Timeliness. Adalah ketersediaan informasi yang terbaharui pada satu waktu.

Equity Implementation Model (EIM) adalah model yang digunakan untuk mengevaluasi sistem informasi melalui perspektif penerimaan pengguna maupun resistensi pengguna. EIM memiliki 3 level dalam melakukan evaluasi antara lain adalah level 1 yaitu Change in equity status of the user (self), level 2 Comparison with the employer dan level 3 Comparison with other users.

\subsubsection{Fokus Kemanfaatan}

Fokus evaluasi yang ketiga adalah kemanfaatan. Pada fokus ini, model-model evaluasi digunakan untuk mengukur hampir semua aspek atau faktor mulai dari organisasional, SDM, teknologi, proses dan banyak lagi sesuai dengan kerangka kerja masing-masing model. Model-model yang tergolong fokus kemanfaatan memiliki karakteristik tersendiri yaitu sistem informasi tersebut dibangun maupun diadakan khusus untuk organisasi tertentu dan untuk kegiatan atau proses bisnis spesifik yang antara satu organisasi dengan organisasi lainya memiliki ciri khas atau perbedaan. Model evaluasi ini sangat cocok digunakan untuk mengukur tingkat keberhasilan sistem informasi yang menyediakan layanan internal Government to Government (G2G) yang diadakan secara khusus dalam implementasi e-government dimana aspek yang diukur lebih kompleks dan komperhensif. Model evaluasi yang termasuk dalam fokus kemanfaatan antara lain adalah ISSM, HOT-Fit dan ITPOSMO. 
Pada tahun 1992, Delone dan McLean [48] melakukan sintesis terhadap penelitian - penelitian terdahulu mengenai kesuksesan dan kegagalan sistem informasi dan membuat body of knowledge untuk memberikan panduan pada penelitian berikutnya yang dinamai Information System Success Model (ISSM). Dalam metode ISSM, terdapat 6 dimensi untuk melakukan evaluasi sistem informasi yaitu system quality, information quality, use, user satisfaction, individual impact dan organizational impact. Kemudian pada tahun 2003, Delone \& Mclean menyempurnakan metodenya dengan menambahkan service quality serta mengganti individual impact dan organizational impact dengan net benefit.

HOT-Fit merupakan pengembangan dari ISSM yang diombinasikan dengan beberapa studi lain yang dilakukan oleh Yusof [49]. Metode ini dikhususkan untuk mengevaluasi sistem informasi pada dunia kesehatan dimana organisasi pada sektor kesehatan harus memiliki kemampuan untuk menyiapkan pegawainya dalam mengadaptasi suatu teknologi baru maupun migrasi antar teknologi. HOT-Fit memiliki 3 aspek dan dimensi yang berbeda di tiap aspeknya antara lain :

- Aspek "Human". Memiliki dimensi system use dan user satisfaction.

- Aspek "Organization". Memiliki dimensi structure dan environment.

- Aspek "Technology". Memiliki dimensi system quality, information quality serta service quality.

Model ITPOSMO menggunakan pendekatan gap antara desain dan implementasi (realitas) untuk melakukan evaluasi terhadap sistem informasi dari suatu organisasi. Model yang dikembangkan oleh Heeks [50] ini melakukan analisa gap pada 7 dimensi yaitu :

- Information. Yaitu informasi baik formal maupun informal.

- Technology. Adalah domain yang mengevaluasi teknologi yang digunakan dalam sistem informasi.

- Processes. Merupakan aktifitas yang dilakukan oleh unit atau bagian organisasi yang relevan. Baik proses yang berkaitan dengan informasi maupun proses bisnis.

- Objectives and values. Sering menjadi dimensi yang paling penting dimana dimensi ini meliputi strategi, kebijakan dan budaya organisasi.

- Staffing and skills. Meliputi sumber daya manusia dan kompetensinya.

- Management systems and structures. Keseluruhan sistem manajemen yang dibutuhkan untuk mengatur organisasi beserta cara organisasi tersebut terstruktur baik formal maupun non formal.
- Other resources. Sumber daya lainya seperti waktu dan uang.

\section{KESIMPULAN}

Pemerintah baik pusat maupun daerah serta lembaga-lembaga dibawahnya telah mengalokasikan anggaran yang besar tiap tahun anggaran untuk sistem informasi baik dalam pengadaanya maupun operasionalnya sebagai upaya penerapan $e$ government. Namun demikian upaya tersebut diatas seringkali menemui kegagalan. Untuk meminimalisir kegagalan-kegagalan tersebut maka perlu dilakukan analisis kegagalan sistem informasi di sektor pemerintah beserta jajaranya guna megurangi resiko kegagalan sistem informasi dimasa yang akan datang.

Dari studi literatur yang dilakukan terhadap 36 jurnal dan artikel, maka dapat disarikan faktor-faktor penyebab kegagalan kedalam 5 dimensi, 20 indikator, 8 model evaluasi sistem informasi serta 3 fokus evaluasi. Dimensi tersebut antara lain adalah organisasi (dengan indikator dukungan \& komitmen pimpinan; hukum, politik \& regulasi; keuangan; strategi \& manajemen resiko), SDM (dengan indikator sosial \& budaya; motivasi; kompetensi TIK; pendidikan \& pelatihan), teknologi (dengan indikator pusat data; konektifitas; sarana \& prasarana pengguna; keamanan \& privasi), layanan (dengan indikator komunikasi; kualitas \& dukungan layanan; data \& informasi), serta proses (dengan indikator perencanaan; kompleksitas; kebutuhan pengguna \& BPR; interoperabilitas \& integrasi, manajemen proyek).

Adapun model evaluasi yang berhasil diekstraksi adalah TAM, TRA dan UTAUT yang termasuk dalam fokus penggunaan; HOT-Fit dan ITPOSMO yang termasuk dalam fokus kemanfaatan serta EUCS dan EIM yang termasuk dalam fokus kepuasan pengguna.

\section{DAFTAR PUSTAKA}

[1] United nation. 2014. E-GOVERNMENT SURVEY 2014.

[2] R. Meiyanti, B. Utomo, D. I. Sensuse, dan R. Wahyuni. 2019. "E-Government Challenges in Developing Countries: A Literature Review"., 2018 6th Int. Conf. Cyber IT Serv. Manag. CITSM 2018, no. Citsm, pp. 1-6.

[3] E. Loukis dan Y. Charalabidis. 2011. "Why do e-government projects fail? Risk factors of large information systems projects in the Greek public sector: An international comparison"., Int. J. Electron. Gov. Res., vol. 7, no. 2, pp. 59-77.

[4] R. Heeks. 2006. "Health information systems: Failure, success and improvisation", Int. J. Med. Inform, vol. 75 2, pp. 125-137.

[5] Y. Muflihah dan T. D. Susanto. 2017. "Faktor yang Mempengaruhi Warga dan Pemerintah 
dalam Adopsi E-Government: Sebuah Ulasan Sistematis"., J. Teknol. Inf. dan Ilmu Komput., vol. 4 , no. 4 , p. 304

[6] F. Masyhur. 2017. "Penelitian e-Government di Indonesia: Studi Literatur Sistematis dari Perspektif Dimensi Pemeringkatan eGovernment Indonesia (PeGI)"., IPTEK-KOM, vol. 19, pp. 51-62.

[7] B. Kitchenham. 2004. "Procedures for Performing Systematic Literature Reviews"., Jt. Tech. Report, Keele Univ. TR/SE-0401 NICTA TR-0400011T.1, p. 33.

[8] L. Glyptis, M. Christofi, D. Vrontis, M. Del Giudice, S. Dimitriou, dan P. Michael. 2020. "E-Government implementation challenges in small countries: The project manager's perspective"., Technol. Forecast. Soc. Change, vol. 152.

[9] M. Toots. 2019. "Why E-participation systems fail: The case of Estonia's Osale.ee",. Gov. Inf. $Q$. , vol. 36, no. 3, pp. 546-559.

[10] M. Guntur, B. Purwandari, T. Raharjo, I. Solichah, dan L. Kumaralalita. 2018. "Critical Success Factors for information systems development: A case study in e-government," ACM Int. Conf. Proceeding Ser., pp. 29-33.

[11] J. K. Putri. 2018. "Obstacle Factor Analysis of E-Government”., 2018 Int. Conf. Adv. Comput. Sci. Inf. Syst., pp. 57-62.

[12] A. Y. Gheni, Y. Y. Jusoh, M. A. Jabar, dan N. M. Ali. 2017. "The critical success factors (CSFs) for IT projects," J. Telecommun. Electron. Comput. Eng., vol. 9, no. 3-3 Special Issue, pp. 13-17.

[13] H. Choi, M. J. Park, J. J. Rho, dan H. Zo. 2016. "Rethinking the assessment of e-government implementation in developing countries from the perspective of the design-reality gap: Applications in the Indonesian e-procurement system"., Telecomm. Policy, vol. 40, no. 7, pp. 644-660.

[14] J. R. Gil-Garcia dan D. S. Sayogo. 2016. "Government inter-organizational information sharing initiatives: Understanding the main determinants of success," Gov. Inf. Q., vol. 33, no. 3, pp. 572-582.

[15] A. I. Almajed dan P. Mayhew. 2014. "An empirical investigation of IT project success in developing countries"., Proc. 2014 Sci. Inf. Conf. SAI 2014, pp. 984-990.

[16] D. Fitrianah, N. H. Praptono, A. N. Hidayanto, dan A. M. Arymurthy. 2014. "A Conceptual Framework of Critical Success Factors to Develop an Integrated Application of Tuna Fishing Data Management in Indonesia”, pp. 113-118.

[17] H. Elkadi. 2013. "Success and failure factors for e-government projects: A case from Egypt"., Egypt. Informatics J., vol. 14, no. 2, pp. 165173.
[18] J. Rajapakse, A. Van Der Vyver, dan E. Hommes. 2012. "E-Government implementations in developing countries: Success and failure, two case studies"., ICIAFS 2012 - Proc. 2012 IEEE 6th Int. Conf. Inf. Autom. Sustain., pp. 95-100.

[19] J. Floropoulos, C. Spathis, D. Halvatzis, dan M. Tsipouridou. 2010. "Measuring the success of the Greek Taxation Information System"., Int. J. Inf. Manage., vol. 30, no. 1, pp. 47-56.

[20] C. C. Mussi, C. D. do Valle Pereira, R. T. de Oliveira Lacerda, dan E. M. dos Santos. 2018. "Pre-Implementation evaluation of a nationwide information system for university hospitals: lessons learned from a study in Brazil"., Behav. Inf. Technol., vol. 37, no. 3, pp. 217-231.

[21] D. Lehman dan C. Ruzich. 2016. "Identifying the Critical Success Factors for Information Systems to Manage Sponsored Research Activities at Institutions of Higher Education"., J. Inf. Syst. Appl. Res., vol. 10, no. 3, p. 4.

[22] R. Sweis. 2015. "An Investigation of Failure in Information Systems Projects: The Case of Jordan," J. Manag. Res., vol. 7, no. 1, p. 173.

[23] A. I. Almajed dan P. Mayhew, 2013, "The critical success factors of IT projects in Saudi Arabian public organizations", Entrep. Vis. 2020 Innov. Dev. Sustain. Econ. Growth - Proc. 20th Int. Bus. Inf. Manag. Assoc. Conf. IBIMA 2013, vol. 1, no. September 2014, pp. 849-856.

[24] M. Abouzahra. 2011. "Causes of failure in Healthcare IT projects"., 3rd Int. Conf. Adv. Manag. Sci., vol. 19, pp. 46-50.

[25] H. S. A. Nawi, A. A. Rahman, dan O. Ibrahim. 2011. "Government's ICT project failure factors: A revisit," 2011 Int. Conf. Res. Innov. Inf. Syst. ICRIIS'11, pp. 2-7.

[26] S. ELKheshin dan N. Saleeb. 2020. "ASSESSING THE ADOPTION OF EGOVERNMENT USING TAM MODEL: CASE OF EGYPT Sara," Int. J. Manag. Inf. Technol. Vol.12, vol. 12, no. 1, pp. 1-14.

[27] M. Al-Emran, V. Mezhuyev, and A. Kamaludin. 2018. "Technology Acceptance Model in Mlearning context: A systematic review," Comput. Educ., vol. 125, pp. 389-412.

[28] S.-C. Chen, S.-H. Li, dan C.-Y. Li. 2011. "RECENT RELATED RESEARCH IN TECHNOLOGY ACCEPTANCE MODEL: A LITERATURE REVIEW," Aust. J. Bus. Manag. Res., vol. 1, no. 9, pp. 124-127.

[29] H. E. Çelik dan V. Yilmaz. 2011. "Extending the technology acceptance model for adoption of e-shopping by consumers in Turkey"., $J$. Electron. Commer. Res., vol. 12, no. 2, pp. 152 164.

[30] D. K. Mohanachandran dan N. S. Govindarajo. 2020. "Theory of reasoned action and citizen's voting behaviour", Pertanika J. Soc. Sci. Humanit., vol. 28, no. 1, pp. 695-715. 
[31] O. C. Otieno, S. Liyayla, dan B. C. Odongo, 2015, "Theoretical and Practical Implications of Applying Theory of Reasoned Action in an Information Systems Study"., OALib, vol. 02, no. 12, pp. 1-5.

[32] R. J. Angelina, A. Hermawan, dan A. I. Suroso. 2019. "Analyzing E-Commerce Success using DeLone and McLean Model"., J. Inf. Syst. Eng. Bus. Intell., vol. 5, no. 2, p. 156.

[33] H. P. Steinbacher. 2013. "Evaluation by using the information system success model"., Proc. IADIS Int. Conf. Inf. Syst. 2013, IS 2013, pp. 361-364.

[34] H. Gunawan, B. L. Sinaga, dan W. P. Sigit Purnomo. 2019. "Assessment of the readiness of micro, small and medium enterprises in using Emoney using the unified theory of acceptance and use of technology (UTAUT) method"., Procedia Comput. Sci., vol. 161, pp. 316-323.

[35] K. B. Shiferaw dan E. A. Mehari. 2019. "Modeling predictors of acceptance and use of electronic medical record system in a resource limited setting: Using modified UTAUT model"., Informatics Med. Unlocked, vol. 17, no. April, p. 100182.

[36] V. Venkatesh, J. Y. L. Thong, dan X. Xu. 2012. "Consumer Acceptance And Use of Information Technology: Extending The Unified Theory of Acceptance And Use of Technology"., MIS Q., vol. 36, no. 1, pp. 157-178.

[37] R. Pauluzzo dan E. F. Geretto. 2018. "Validating the EUCS model to measure the level of satisfaction of Internet users in local banks in Italy"., J. Organ. End User Comput., vol. 30, no. 1, pp. 66-81.

[38] B. Prasetyo, R. W. E. Yulia, dan Felisia. 2018. "Measuring end-user satisfaction of online marketplace using end-user computing satisfaction model (EUCS Model) (Case study: Tokopedia.com)"., Proc. 2017 4th Int. Conf. Comput. Appl. Inf. Process. Technol. CAIPT 2017, vol. 2018-Janua, pp. 1-5.

[39] L. M. Erlirianto, A. H. N. Ali, dan A. Herdiyanti, 2015, "The Implementation of the Human, Organization, and Technology-Fit (HOT-Fit) Framework to Evaluate the Electronic Medical Record (EMR) System in a Hospital"., Procedia Comput. Sci., vol. 72, pp. 580-587.

[40] D. Napitupulu, D. I. Sensuse, dan Y. G. Sucahyo. 2017. "Sosio-technical factors of egovernment implementation"., Int. Conf. Electr. Eng. Comput. Sci. Informatics, vol. 4, no. September, pp. 690-695.

[41] A. Fauzie, D. I. Sensuse, I. Budi, W. C. Wibowo, Fitroh, dan R. Kunthi. 2017. "Propose of critical success factors for e-Hajj implementation in Indonesia"., J. Eng. Appl. Sci., vol. 12, no. 7, pp. 1806-1810.

[42] H. W. Kim. 2011. "The effects of switching costs on user resistance to enterprise systems implementation"., IEEE Trans. Eng. Manag., vol. 58, no. 3, pp. 471-482.

[43] T. J. Hess, K. Joshi, dan A. L. McNab. 2010. "An alternative lens for understanding technology acceptance: An equity comparison perspective"., J. Organ. Comput. Electron. Commer., vol. 20, no. 2, pp. 123-154.

[44] H. Lu, P. Lin, C. Lo, dan M. Wu. 2012. "A Review of Information System Evaluation Methods"., Int. Conf. Softw. Comput. Appl. (ICSCA 2012) IPCSIT, vol. 41, no. Icsca, pp. 243-248.

[45] F. D. Davis. 1989. "Perceived usefulness, perceived ease of use, and user acceptance of information technology"., MIS Q. Manag. Inf. Syst., vol. 13, no. 3, pp. 319-339.

[46] V. Venkatesh, M. G. Morris, G. B. Davis, dan F. D. Davis. 2003. "USER ACCEPTANCE OF INFORMATION TECHNOLOGY:TOWARD A UNIFIED VIEW”., MIS $Q$., vol. 27, pp. 425478.

[47] W. J. Doll dan G. Torkzadeh. 1988. "The Measurement of End-User Computing Satisfaction”., MIS Q., vol. 12, no. 2, pp. 259274.

[48] W. H. Delone dan E. R. McLean. 1992. "Informationsystems success:The quest for the dependent variable"., Inf. Syst. Res., vol. 3.

[49] L. Yusof, MM; Paul, RJ; dan Stergioulas. 2006. "Towards a framework for Health Information System Evaluation, School of Information System"., Proc. 39th Hawaii Int. Conf. Syst. Sci., vol. 01, no. C, pp. 1-10.

[50] R. Heeks. 2002. "The Information Society : An International Journal Information Systems and Developing Countries: Failure, Success, and Local Improvisations Information Systems and Developing Countries : Failure, Success , and Local Improvisations"., Inf. Soc. An Int. J., vol. 18 , no. 2, pp. 101-112. 